\title{
TRABALHO E SINDICALISMO: RESIGNIFICANDO A CRISE
}

\author{
Maria Aparecida Bridi ${ }^{1}$ \\ Silvia Maria de Araújo ${ }^{2}$
}

\section{Resumo}

As recentes transformações no mundo do trabalho vêm acompanhadas de uma leitura de crise generalizante e apocalíptica para o trabalho e as organizações dos trabalhadores, alastrando a idéia de crise, apresentada como uma auto-explicação universalista para o sindicalismo. O presente artigo demonstra a importância de problematizar o conceito de crise e propõe que as crises precisam ser contextualizadas empiricamente e entendidas em sua natureza. A metodologia empregada tem como pressuposto que a realidade é ambivalente, complexa, multifacetada. Expõe as manifestações de crise no sindicalismo - expressa na fragmentação dos trabalhadores, na anunciada crise de identidade e na desmobilização frente às tentativas de desmonte da relação salarial.

Palavras-chave: Sindicalismo; Crise; Identidade.

\section{Abstract}

Recent changes in the world of labor are accompanied by the generalization of apocalyptic readings on the worker's organizations and on labor itself, spreading the idea of crisis, presented by many as a self-explanatory and universal truth for syndicalism. The present article demonstrates the importance of questioning the concept of crisis, proposing it should be positioned in an empirical context and understood in its nature. The methodology employed in this text premises reality as ambivalent, complex and multi-sided, exposing the manifestations of the crisis in syndicalism, such as the fragmentation of workers' collectivities, the crisis of identity and the demobilization against the constant attempts to undermine wages.

Keywords: Syndicalism; Crisis; Identity.

\footnotetext{
${ }^{1}$ Socióloga, Doutora em Sociologia (UFPR), Pesquisadora do GETs Trabalho e Sociedade. Rua Ozório Duque Estrada, 790. CEP: 82520-470, Curitiba-PR, Brasil. (55) (41) 32629381.E-mail: bridi@ b.com.br;

${ }^{2}$ Socióloga, Professora do Programa de Pós-Graduação em Sociologia da UFPR. Rua da Paz, 37. CEP: 80060160, Curitiba-PR, Brasil. (55) (41) 32627563.E-mail: saraujo@swi.com.br.
} 


\section{Introdução}

Das mudanças no trabalho surgiram antagônicas posições a respeito da instituição sindicato, sobre sua falência ou não, sua fragilidade e dúvidas quanto ao seu papel social. $\mathrm{O}$ diagnóstico de crise nos cenários internacional e nacional, no entanto, revela realidades distintas que não permitem generalizações apriorísticas da crise sindical, tampouco, o tratamento dessas deve ser dado como algo completamente novo. Algumas vertentes teóricas chegaram a defender a tese de um novo modo de produção. No entanto, como alerta Harvey (1993) é necessário distinguir o que de fato é novo, ou seja, aquilo que não encontra referência na história passada. Possivelmente, a velocidade das mudanças e a transitoriedade dos acontecimentos sejam elementos novos, mas o modo de produção capitalista permanece e se revigora nos ensejos de suas crises, como demonstra a realidade empírica.

É, portanto, a crítica à leitura de crise generalizante e apocalíptica para o trabalho e as organizações dos trabalhadores - que alastrou uma idéia de crise como auto-explicação universalista para o sindicalismo - que motivou este estudo. Objetiva-se problematizar o conceito de crise, cuja banalização nas últimas décadas redundou em perda do significado. Adota-se a perspectiva de que as crises precisam ser contextualizadas empiricamente, como uma metodologia que expõe as manifestações de crise no sindicalismo, partindo do pressuposto de que não existe uma realidade única e homogênea e as crises fazem parte da auto-constituição da sociedade.

Propõe-se discutir, neste texto, uma das crises que atingem os trabalhadores: a anunciada crise de identidade e seus reflexos na instituição sindical. A análise, envolvendo os metalúrgicos na indústria automobilística e o sindicato paranaense da categoria nos anos 2000, demonstra adaptações e mudanças nas suas formas de ação, porém, as dificuldades que se apresentam ao sindicalismo não significam que se possa decretar a morte da ação coletiva.

Composta de três partes, a reflexão se detém na condição da crise percebida nos sindicatos atuais, no caráter de novidade que a circunda e tece uma crítica à idéia generalizada de crise. Na segunda parte, o texto foca a atenção na questão da construção da identidade dos trabalhadores e do sindicalismo em face do fenômeno da segmentação presente no interior das empresas e no mercado de trabalho, dificultando a mobilização da categoria. Por último, os reflexos da crise empírica e teórica sobre a realidade sindical são vistos pelo prisma dos desafios que se apresentam ao sindicalismo diante das transformações no movimento de acumulação do capital e no mundo do trabalho. 


\section{Sindicatos hoje: uma crítica à generalização do discurso de crise e seu caráter novidadeiro}

Apesar de não se tratar de um único sindicalismo nas diversas partes do mundo ocidental, em linhas gerais, costuma-se apresentar que, enquanto no começo do século XX o sindicalismo representou uma força social em ascensão, no seu final, passou a ser analisado como uma instituição enfraquecida e com baixa capacidade de resposta às mudanças no mundo do trabalho contemporâneo.

Como não se pode analisar produção flexível, por exemplo, enquanto um padrão único, nos distintos países, também a realidade sindical tem se revelado diversa e heterogênea tanto nos níveis de sindicalização quanto na força de mobilização de diferentes categorias profissionais. As especificidades no interior do sindicalismo não permitem que prevaleçam explicações generalizadoras e deterministas, nem que predomine um padrão universal de interpretação, uma vez que a ação sindical depende dos agentes sociais envolvidos e da formação histórica de cada país, região, categoria e setor econômico. Questões aparentemente semelhantes possuem significados muito diversos em diferentes contextos históricos e culturais e, ao representarem uma heterogeneidade sindical, não permitem uma análise de base única e, muito menos, definitiva para os rumos do sindicalismo, numa realidade em transição.

Apresenta-se, de modo geral, entre outros sintomas de crise para o sindicalismo: a redução das taxas de filiação e das greves, a dificuldade do sindicato em representar o conjunto de trabalhadores formais e informais, a individualização crescente das relações de trabalho, a redução da militância, a descentralização das negociações. Embora seja possível fazer classificações identificando, por exemplo, países com forte, média ou baixa ação sindical, como o fez Rodrigues (1999), existe dificuldade em realizar diagnósticos gerais a respeito da crise no sindicalismo nos diversos países. A fragilização e o refluxo da ação sindical, identificados a partir dos anos 1980, não ocorreram de forma homogênea nem simultânea em todos os países. As teses de crise do sindicalismo europeu apenas em parte são similares no Brasil ou demais países latino-americanos. As trajetórias históricas são distintas. Enquanto os trabalhadores europeus conquistaram um Estado de Bem-Estar no bojo da Guerra Fria, por meio de um padrão de organização sindical, na América Latina isso não ocorreu em plenitude. A industrialização tardia e os regimes políticos ditatoriais e autoritários resultaram numa conformação não homogênea dos trabalhadores, em termos de condições de 


\section{DIVERS@!}

trabalho e de organização sindical. Portanto, as crises não se deram simultaneamente e o movimento operário, na América Latina, tem tido situações de crescimento e decrescimento desde os anos 1980, embora muito diferenciadas. As interpretações de crise sindical seguem o mesmo compasso.

Enquanto o sindicalismo europeu se encontrava em crise, na década de 1980 - com a redução das bases sindicais em função do desemprego e o declínio da filiação e das taxas de greves - no Brasil, assistia-se o ressurgimento da ação sindical e grevista. Conjugam-se para esse desempenho em um decênio (1978-1988), o surgimento do novo sindicalismo com período de grandes greves (fins da década de 1970) e a Constituição de 1988, que liberou a organização de sindicatos e esses se multiplicaram. O sindicalismo encontrava-se em pleno vigor, tendo crescido o número de sindicatos e a capacidade organizativa e de representação dos mesmos. O chamado "novo sindicalismo" foi identificado pela literatura como combativo e marcado pela conquista de direitos, politização da classe trabalhadora e por tentativas de romper com a estrutura do sistema corporativo do sindicalismo brasileiro, visando a remodelação da estrutura sindical. Não representou o sindicalismo no seu todo.

As análises do movimento sindical precisam atentar para as especificidades no interior do sindicalismo, pois as respostas sindicais variam entre os países e categorias, como demonstra o sindicalismo no Paraná ligado aos metalúrgicos do setor automotivo. $\mathrm{O}$ movimento real, ainda que se trate de um real construído, pode contribuir para uma análise de crise que não represente terminalidade.

Tratar o sindicalismo como agente da revolução social e com uma missão histórica emancipadora, fundado mais na possibilidade de futuro, de um devir, do que na própria condição do sujeito sindicato tende a resultar em distorções teóricas. Os sindicatos nasceram vinculados ao capitalismo e, portanto, com limitações. Como reconhece Karl Marx (s.d.), os sindicatos "são deficientes, de modo geral, por se limitarem a uma luta de guerrilhas contra os efeitos do sistema existentes, em lugar de ao mesmo tempo se esforçarem para mudá-lo, em lugar de empregarem suas forças organizadas como alavanca para a emancipação final da classe operária, isto é, para a abolição definitiva do sistema de trabalho assalariado" (Marx, s.d., p. 378). A identificação deste autor clássico da sociologia acerca dos limites do sindicalismo não o impediu de reconhecer a importância do papel pedagógico que exerce o sindicato junto aos trabalhadores. Por meio de lutas e greves permite acontecer um aprendizado de classe social e o confronto entre o capital e o trabalho. 
É evidente que o crescimento do desemprego, da informalidade, da insegurança no emprego e da segmentação, advindos com as mudanças ocorridas nas relações de produção e no mercado de trabalho, colocaram desafios e problemas para os trabalhadores e suas organizações sindicais. A crise no sindicalismo não resulta apenas das alterações de base técnica, isto é, em função das mudanças na produção, mas também da orientação política que prevaleceu a partir da década de 1970, na Europa, e de 1990, no Brasil. Além disso, tal situação histórica se fez palco de uma crise teórica3. Existe dificuldade de compreensão das várias realidades em transição e sua transversalidade, cuja visão de prevalência das rupturas precipitou a obsolescência de teorias e de conceitos da sociologia clássica.

A retração da ação sindical, no entanto, só pode ser explicada pela combinação de múltiplos fatores, pois é parte de uma realidade complexa e ambivalente. Não sugere, portanto, o descarte e sim a aproximação entre as teorias, uma vez que é possível acumular conhecimento a partir de teorias conflitantes e em competição. A própria história não se desenvolve numa linha única como supõem os positivistas, tampouco a sociedade é uma só e isso revela que o princípio de universalidade é insuficiente para a explicação de uma realidade que não está dada, nem é completa. É mutante, complexa e exige uma forma de pensar também complexa.

Nesse tempo de transição, para dar conta de uma ação é preciso compreendê-la na sua singularidade e na relação com outros fenômenos, como orienta Weber (1991). Explicar um fenômeno social exige atenção também às ações individuais, pois há um entrelaçamento entre indivíduo e sociedade que não pode escapar à análise. Metodologicamente, implica também em não dissociar o movimento sindical da sua história e do desenvolvimento do capitalismo, em suas transformações e permanências, permitindo que se contraponha às teses que sugerem o fim da ação ou reação dos trabalhadores e suas instituições de representação.

\footnotetext{
${ }^{3}$ Para Sorj (2000, p. 26), a sociologia do trabalho ficou "imprensada por duas visões opostas": uma que relativiza as mudanças, considerando que o capitalismo permanece com os mesmos princípios destacados pela sociologia clássica e, outra, indicando que tudo mudou e o trabalho não se constitui mais uma categoria-chave para a análise da realidade, em vista da perda de sua centralidade para a esfera do consumo. Autores como Bourdieu, Cardoso, Castel, Leite, Oliveira, Sousa Santos, Thompson, Sader e outros não se enquadrem nessa polaridade, onde se encontram Offe, Gorz, Habermas.
} 


\section{DIVERS@!}

\section{A crise não é uma novidade}

O recuo na história demonstra que a crise presente nas diversas dimensões das relações sociais não é a única de que se tem notícia na história do capitalismo. Marx e Engels (s.d. p. 24) já demonstravam a situação de crise pela qual passava a sociedade européia no momento de consolidação do sistema capitalista. Chega-se mesmo a aventar a possibilidade de correspondência entre mudanças bruscas e ou intensas com crises. Nesse sentido, a crise seria a própria imanência da mudança.

Enquanto uma formação histórica, o capitalismo é assolado, periodicamente, por crises econômicas que desencadeiam crises sociais. A comparação entre as crises econômicas - que redundaram também em crises sociais e políticas - permite identificar semelhanças entre os processos de crise ao final dos séculos XIX e XX. Em ambas as crises, os processos de produção foram revolucionados por inovações técnicas resultando em intensificação do trabalho, incremento da produtividade e mudanças no capitalismo e ambas foram vividas como verdadeiras revoluções, "novidades excepcionais", como afirmam Chesnais et al. (2003). Se analisadas a fundo, no entanto, possibilitam questionar o caráter de novidade dado a esses períodos de mudanças.

Da mesma forma, quando se analisa o tempo presente. Ao contrário do que anuncia a literatura, observa-se que tendências atuais tidas como inéditas são, em verdade, familiares, como demonstra a história da humanidade em seu desenvolvimento econômico de diferentes momentos. O que difere "é a escala, o âmbito e a sofisticação técnica da atual expansão financeira", as quais são maiores que as expansões anteriores. (Arrighi, 1996, p.4-7).

Não se trata de negar as mudanças, mas afirmar que muitas delas - incluindo o discurso de crise que vem perdurando - apresentadas como novidades são faces redimensionadas de fenômenos anteriores, resultantes de profundas transformações no funcionamento do modo de produção capitalista, que mantêm como eixo o controle e a exploração do trabalho, a par da tendência de redução nos padrões médios dos salários. Assim, é preciso questionar a banalização da crise estendida por todo o tecido social, cujas interpretações, como a de crise do sindicalismo, levam a afirmar que é normal "estar em crise", sem que isto signifique o fim. Convém conceituar crise, a partir da interdependência entre os dois sentidos: o moderno, como incerteza e indeterminação e no sentido grego como decisão (Morin s.d, p. 115). A crise "é um momento indeciso e ao mesmo tempo decisivo" (idem), portanto, reflete uma transição que se encontra recoberta por desordens, 


\section{DIVERS@!}

antagonismos, conflitos e contradições inerentes ao capitalismo. A própria mudança contém um caráter crísico.

A supervalorização da novidade dada à crise no que toca aos sindicatos, tem cunho ideológico, na medida em que produz explicações dissociadas da história e serve aos propósitos neoliberais de desqualificação das organizações dos trabalhadores.

É certo que as circunstâncias são mais adversas para o sindicalismo e para a ação coletiva, já que o neoliberalismo é hostil aos sindicatos, mas isso não significa a morte da ação. Ao contrário das teses sobre o fim do sindicalismo, os trabalhadores encontram outros meios, outras brechas para se reorganizarem como vêm demonstrando inúmeras experiências sindicais, dentro e fora das empresas, inclusive na realidade local estudada. O sindicato, como uma organização complexa e parte de um todo igualmente complexo, pede estudos a partir de múltiplas dimensões.

\section{Sindicalismo, identidade e fragmentação dos trabalhadores}

A literatura sociológica reconhece que os trabalhadores vivem uma crise de identidade com reflexos importantes para o movimento sindical. Considera como um dos elementos de crise sindical, a dificuldade do processo de identificação dos trabalhadores, dadas as transformações no âmbito do trabalho. Isso instiga analisar como as mudanças que ocorrem no processo de produção interferem na identidade do trabalhador. Aliada a essa análise, discute-se de que forma as transformações em curso afetam a identidade do sindicato enquanto instituição.

A presente abordagem não analisa a identidade do ponto de vista da subjetividade ou da psicologia, mas de uma identidade que envolve a experiência e a consciência de pertencimento a um coletivo e de um compartilhamento de referencial comum. Também não se confunde com papéis sociais, pois como distingue Castells (1999, p. 23), "as identidades organizam significados, enquanto papéis organizam funções". Para esse autor a identidade é fonte de significado e experiência de um povo. A identidade de trabalhador e do sindicato, enquanto atores sociais, são construções históricas e articuladoras de projetos culturais, sociais e políticos que atravessam o pensamento social.

As teses que propugnam o fim do sindicalismo e que têm relativizado o trabalho na constituição do sujeito, analisam que o trabalhador já não se identifica como categoria e, conseqüentemente, não se aglutina em torno de interesses comuns que o empurrem para a 


\section{DIVERS@!}

ação coletiva. Tradicionalmente, a teoria sociológica compreende que identidade e trabalho se encontram articulados. O trabalho é chave na formação de identidade do indivíduo e da consciência de pertencer a determinado grupo social. Identidade pessoal e social encontram-se imbricadas e as implicações dessa pertença constitui uma identidade social analisa Jacques (2002).

Analisa Araújo (2004, p.24) que a identidade é construída como produto institucional, justamente "porque os atores individuais são referidos ao grupo e/ou classe social a que pertencem e a ele aderem para intermediar ações, estabelecer normas de conduta. Em um e em outro nível, ela é elaborada como produto das interações entre um conjunto de indivíduos, sejam trabalhadores, sindicalistas, empresários, colocados concretamente em situação de confronto".

A capacidade da ação coletiva organizada tem a ver com a capacidade das instituições desenvolverem uma identidade. $\mathrm{O}$ aparecimento de uma identidade que transforma a ação coletiva num ator coletivo ocorre ao se definir as fronteiras daquela ação. Isto significa que a identidade é um constructo social que se forma na ação e no discurso. Dessa forma, a análise da crise ou dos descaminhos e obstáculos no processo de identificação do trabalhador têm a finalidade de refletir e teorizar a respeito das mudanças que podem colocar em xeque identidades construídas, seja no plano real, seja no plano teórico.

A construção da relação salarial no século XX, apesar de não homogênea entre os diversos países, deu ao trabalho o status de meio para a cidadania. Os sujeitos sociais obtiveram garantias e direitos, justamente por participarem da condição assalariada e foi o contrato de trabalho que, ao regulamentar juridicamente as relações de trabalho, de compra e venda da força de trabalho, possibilitou a construção de identidade do assalariado. Esse processo resultou numa desindividualização, na medida em que inseriu os trabalhadores em regimes gerais, convenções coletivas, regulações públicas do direito do trabalho e de proteção social (Castel, 1998, p. 600). Processo esse, invertido nas condições do capitalismo contemporâneo sob o regime de produção flexível e enxuta, como ocorre na indústria automobilística, pois a individualização integra o teor dos contratos, acordos, relações de trabalho e as negociações.

A partir dos anos 1970, a redução dos empregos formais e a desregulamentação do trabalho mergulham os trabalhadores na incerteza e vulnerabilidade em vista da perda ou da fragilização de uma relação que sustenta identidades individuais, sociais e coletivas. A flexibilização das relações de trabalho levou à ampliação de novas precárias formas de 
trabalho - em tempo parcial, com contrato por tempo determinado, trabalho em domicílio, subcontratação, trabalho informal - que atingiram os sindicatos, pois dificultam a formação de uma identidade comum que é chave para a aglutinação de interesses e a ação coletiva.

As análises sociológicas apontam que o emprego estável e de qualidade possibilita a criação de sociabilidades e verdadeiras redes de interação, dentro e fora do local do trabalho. Os "empregos estáveis, ainda que mal remunerados, trazem benefícios subsidiários de monta que podem perfeitamente suplantar os benefícios monetários de ocupações mais concorrenciais", afirma Cardoso (2000, p.75-76).

A heterogeneidade dos contratos de trabalho verificada nas plantas industriais enxutas e flexíveis - característica das montadoras de nova geração - atinge a construção de identidade do ser trabalhador. Os trabalhadores vivem um processo de descontinuidade permanente, explicado pela rotatividade no trabalho devido ao desemprego e à oscilação entre empregos formais e informais, o que justifica pensar em termos de identidades transitórias, fragmentadas, mas que se constróem e reconstróem continuamente nas ações.

A crise de identidade é uma crise inscrita na pulverização da classe trabalhadora, mas fruto também de uma dificuldade teórica em explicar uma mudança que não se coaduna com uma imagem construída (real e teórica) em torno do operário tradicional, típica da sociedade industrial, sobretudo a fordista, que predominou no século XX. A indústria automobilística, que era constituída de milhares de trabalhadores, opera hoje com o número reduzido deles, comparativamente com as plantas fordistas onde os trabalhadores se concentravam em uma única empresa ou em grandes empresas.

$\mathrm{Na}$ fábrica flexível e robotizada, os trabalhadores encontram-se dispersos entre centenas de fornecedores, com diferenciadas formas de contrato de trabalho e exercendo múltiplas atividades. A polivalência do trabalhador, no contexto das empresas reestruturadas e das fábricas de nova geração, resulta num esvair-se do sentimento de pertencimento a uma categoria, pois a troca de funções e tarefas produz uma perda de identidade entre a função, a atividade exercida no trabalho e o trabalhador. Diversas falas de entrevistas mostram que os trabalhadores percebem esse fenômeno:

Dentro da empresa hoje você não acha a função, o salário por função. Antigamente era normal você ter um piso: o mecânico, o eletricista, o soldador. Hoje estão dentro da categoria. Então, a empresa dentro da categoria, ela coloca funções. Agora cabe perguntar: 'como é que você sabe quanto tempo você vai levar para chegar naquela função'? Antes você sabia que chegava na empresa, entrava (...), ficava um ano nessa função, daí você tinha uma 
promoção e podia chegar até lá em cima. Hoje, você não tem mais essa visão, você faz de tudo. Como é que vai dividir? (Entrevista n. ${ }^{\circ} 5$ com dirigente sindical, ago. 2004).

Numa estrutura fordista, o trabalhador conseguia acompanhar sua carreira e ascender quando incorporava novas funções. A produção se dava a partir de um conjunto específico de funções, nas quais, o "posto de trabalho pré-determinado exigia uma série de qualificações específicas e também pré-determinadas que iam sendo adquiridas pelos trabalhadores treinados - muitas vezes pelas próprias empresas ou pelas escolas técnicas - para exercê-las" analisa Manzano (2004, p. 73). Na Volvo, nos anos 1990, por exemplo, ao fazer a reconversão industrial e a Volkswagen-Audi e a Renault, desde o início de suas atividades no Paraná (fins dos anos 1990), estruturaram as linhas de produção em células, times ou sob o conceito de Equipes Auto-Gerenciáveis - EAG, modificando os postos de trabalho e pulverizando os trabalhadores no chão de fábrica4. Isso sinaliza uma crise de identificação onde o trabalhador já não reconhece a sua função, seja como soldador, torneiro ou ferramenteiro, própria da indústria automobilística tradicional e a sua categoria, em vista das múltiplas funções que exerce, especialmente os mais velhos, pois os mais jovens são iniciados no novo contexto de relações. Acrescente-se a isso o hiato existente entre a formação e a atividade que esse trabalhador desempenha dentro da empresa. Para contratar, a empresa "exige um SENAI, um CEFET, para você aprender a ser soldador, ser desenhista, ser técnico, engenheiro e você vai ser é montador. Hoje, você pega um aprendiz do SENAI, ele aprende: mecânica! Mas, a função de mecânico extinguiu, ele vai aprender mecânica e dentro da empresa [irá trabalhar] como lixador, na pintura" (Entrevista n. ${ }^{\circ} 5$ com dirigente sindical, ago.04).

A partir do momento em que este trabalhador passou a exercer múltiplas funções na empresa de produção enxuta, a possibilidade da construção de uma "carreira" profissional, desapareceu.

Além dessas dificuldades quanto às funções, a pesquisa empírica revela mudança no perfil do trabalhador na indústria automotiva. A idade média nas linhas de produção da montagem é de 25 anos, pois entre as novas exigências dessa indústria estão a polivalência, resistência e agilidade física e mental.

\footnotetext{
${ }^{4}$ A Volvo é uma montadora de ônibus e caminhões de origem sueca, instalada em Curitiba-Paraná em fins dos anos 1970, já a Renault, de origem francesa e a Volkswagen-Audi, alemã, se instalaram nos final dos anos 1990. A Volvo passou pela reestruturação produtiva nos anos 1990, visando tornar-se mais competitiva no novo cenário de abertura dos mercados enquanto as outras duas montadoras foram concebidas e projetadas nos moldes da produção flexível e enxuta, ou seja, chegaram com plantas maduras.
} 
A mudança de perfil é sentida pelos dirigentes do Sindicato dos Metalúrgicos da Grande Curitiba - SMC. Estes observam diferenças nas demandas entre trabalhadores casados e solteiros que interferem na disposição da ação. Enquanto o trabalhador casado preocupa-se com a manutenção do emprego, o salário e alguns benefícios, o solteiro, maioria com $2^{\circ}$ grau completo e muitos cursando o ensino superior, tem necessidade de consumo, qualificação e expectativas que não condizem com o que a empresa oferece, por isso, busca reconhecimento e cobra dos níveis hierárquicos superiores e da comissão de fábrica. Os trabalhadores jovens encontram-se mais propensos à mobilização por melhores salários, pois podem correr mais riscos, afirmam os sindicalistas entrevistados.

A propensão para a mobilização desse trabalhador, na realidade local, contradiz em certa medida, as análises que apontam para um jovem indiferente à sua situação no trabalho5. Embora, reconheçam os sindicalistas que esses trabalhadores que se mobilizam para as reivindicações salariais, são pouco politizados e desinteressados dos assuntos sindicais. Afirmam que o interesse é pontual: salários e PLR.

Destaca-se, no entanto, que a mobilização por cláusulas econômicas não é uma novidade exclusiva do tempo atual. A perspectiva histórica e dialética nos recoloca que solidariedade de classe, consciência política dos trabalhadores são construídas por meio de ações intencionais das organizações dos trabalhadores.

Na organização da produção das montadoras por times, células ou EAG, evidenciamse sinais de conflitos que tendem a dificultar a aglutinação de interesses comuns.

O conceito de time auto-gerenciável supõe autonomia para organizar o próprio trabalho e participação dos processos de gestão e decisão. O líder, antes escolhido pela empresa através da carta de versatilidade, que assinala as várias tarefas e habilidades desenvolvidas pelo trabalhador, passa a ser escolhido, nas EAG, pelo próprio grupo e não pela empresa. Na Volvo, que tem esse programa implementado desde os anos 1990, observa-se que, na prática, os trabalhadores possuem pouca autonomia, uma vez que se verifica o quanto o grupo tem que agir para sobreviver.

\footnotetext{
${ }^{5}$ Segundo Heinze et al (1984), pesquisas em países europeus, há mais de 20 anos, apontavam o desinteresse dos jovens pelo movimento sindical em vista de uma crise de identificação, na qual não se reconheciam nas lutas do mundo do trabalho, decorrentes das transformações econômicas, culturais e políticas nas décadas posteriores à Segunda Guerra. Ou seja, para os jovens europeus, o trabalho não se constituía centro de suas vidas. Investigações poderão acompanhar como está o trabalhador jovem em relação aos sindicatos e, também, como isso se aplica à realidade do Brasil.
} 
Esse problema da equipe auto-gerenciável é muito sério. Nós estamos tendo problemas constantes desse tipo de sistema que a Volvo adotou aqui. $\mathrm{Na}$ verdade, é um excelente sistema que foi implantado, mas é um sistema excelente para a empresa. Para os trabalhadores, foi muito ruim porque está gerando conflitos constantemente (...) Atualmente nós estamos com um conflito muito grande na minha área do sistema também, pois venderam uma idéia e não é essa a idéia, que teríamos autonomia e discussões e tal, tal, tal. (Entrevista, n. ${ }^{\circ}$, com Comissão de Fábrica. ago. 2004).

Consta que a escolha do líder nem sempre é feita pelos times. O líder imposto tende a assumir o papel de chefia, a não liderar, mas comandar muitas vezes de forma autoritária: "eles se intitulam chefia, 'eu sou chefia aqui da área, então, tem que fazer isso que eu estou mandando'. E não é bem assim. Por isso, têm os conflitos, mas a Volvo não entende isso" (Entrevista $n^{\circ} 6$ com membros da Comissão de Fábrica ago. 2004). Segundo a Comissão de Fábrica, os conflitos ocorrem principalmente com os trabalhadores que são mais antigos, pois os mais novos acatam de maneira mais submissa as inovações e mudanças e, por não terem vivido processo de organização anterior, não têm consciência da perda de direitos provocada pela desregulamentação do trabalho, sobretudo. A autonomia atribuída a esses grupos é relativa. Restringe-se à esfera da produção e cria divisões dentro do grupo.

Nesta forma de organização, os trabalhadores assumem funções de vigilância, e até de punição para com os que não conseguem cumprir as metas estabelecidas para o grupo. Corrobora, assim, para fragmentar ainda mais o trabalhador no chão de fábrica, dividir os seus interesses no processo de trabalho e criar expectativas e competição internamente entre os pares. Essas relações de produção modificadas enfraquecem os vínculos sociais e substituem a solidariedade de classe por uma espécie de sociabilidade privada, segundo Mello e Silva (2004), o que, evidentemente, tende a se refletir nas organizações de representação dos trabalhadores.

Na Renault, a partir da conquista dos trabalhadores do fim do trabalho aos sábados, passou a haver preocupação coletiva para o cumprimento das metas de produção durante a semana, mobilizando a atenção dos times para não sobrar trabalho. Passou a ocorrer o controle intra-times visando a "responsabilidade produtiva", quando cada um tem que se esforçar ao máximo no período de segunda a sexta-feira, em forte processo de responsabilização do trabalhador: 
E todo mundo tá preocupado em que esse objetivo, essa produção da semana seja feita, porque senão pode acabar ocorrendo uma hora-extra no sábado, um plantão (...). Passou a ter um compromisso, um comprometimento do trabalhador com a produção, maior. Então, o pessoal diz para a manutenção: (...) 'tá na hora de vocês aí da manutenção fazer o serviço, para que eu não precise ficar depois do meu horário ou no sábado (Entrevista n. 3 com membros da Comissão de Fábrica, jul.2004).

É criada, assim, a "condição subjetiva para intensificar o trabalho capacitando o trabalhador a empregar mais força num tempo dado", prevista nas observações de Marx (1975, p. 470) sobre a realidade do sistema capitalista em consolidação, na Europa dos séculos XVIII e XIX. Na moderna produção de veículos, a automatização permite aumentar a velocidade na linha de produção, impondo maior pressão sobre o trabalhador e estímulos de ritmos compassados de trabalho entre os diferentes setores dentro das empresas e entre elas. A vigilância contínua de um trabalhador sobre o outro para o cumprimento das metas tende à eliminação de toda e qualquer porosidade no tempo de trabalho.

As estratégias adotadas pelas empresas visam fazer o trabalhador identificar-se mais com os objetivos do capital e tomar esses como se fossem seus. Buscam desenvolver métodos que criam identidade do trabalhador com a empresa, trabalhando, portanto, na perspectiva de desenvolver interesses comuns. É um processo que, dada a dimensão do desemprego, consegue, em muitas situações, uma 'cooperação forçada' dos trabalhadores, o que tende a contribuir para o deslocamento do âmbito das negociações explícitas ou tácitas da categoria para o espaço local (KREIN, 2001, p 150).

Por outro lado, essa conformação e os métodos organizacionais adotados "criam espaços de discussão e solução dos problemas da empresa, tais como os Círculos de Controle de Qualidade - CCQs, as células, os times de trabalho”, confirma Krein, (idem), significando brechas para a ação coletiva, oportunidades de organização para os trabalhadores.

Os conflitos verificados no interior dos times de trabalho advêm da inversão de interesses entre capital e trabalho que é parte da lógica da organização da produção enxuta. Esse processo ameaça a construção do sentimento do trabalhador pertencer a um coletivo valorizado e que se afirma enquanto categoria profissional. Historicamente, essa identidade de grupo, de um corpo coletivo é um dos elementos mobilizadores da luta operária. Contudo, a ameaça posta por uma produção segmentada não parece ser obstáculo definitivo para a 
existência de uma ação coletiva, visto que a identidade é construída na ação e não se encontra predeterminada no momento em que o trabalhador entra na empresa. As dificuldades postas por esse modelo de produção não têm sido impedimento para a mobilização coletiva no interior de cada empresa, como se observou nas ações dos trabalhadores das montadoras paranaenses.

Ao lado da segmentação e instabilidade produzidas pelo processo da acumulação flexível, identifica-se um novo corporativismo, distinto do corporativismo de Estado que, historicamente, configurou a estrutura sindical brasileira. Agora, verifica-se o poder de atração da empresa que perpassa as práticas de trabalho de persuasão. Cada segmento dos trabalhadores passa a acompanhar os interesses da "sua empresa" e não mais do conjunto da categoria, observa Boito Jr. (1999, p. 168). Este neocorporativismo divide, despolitiza o movimento sindical e permite ao neoliberalismo manter a ação reivindicativa dos trabalhadores dentro de certos limites, desviando-a da luta por direitos sociais.

O neocorporativismo na indústria automobilística resulta, também, do movimento de desconcentração das empresas no cenário global e também nacional. A capacidade de mobilidade das novas plantas possibilita ao capital enfrentar as pressões dos trabalhadores por melhores condições de trabalho e salários com ameaças de fechamento e ou transferência das unidades produtivas para outras fábricas no mundo. A existência de três plantas da Volkswagen, no Brasil, por exemplo, pode servir para moderar a disposição de luta dos trabalhadores, que se vêem ameaçados de perder o emprego se uma planta for fechada. Assim, a competição por empregos pode pôr em xeque a solidariedade dos trabalhadores. No entanto, verifica-se uma situação paradoxal em que a competição pelo emprego e a necessidade de ação conjunta caminham lado a lado. Isto se reflete na predisposição para acordos coletivos unificados nacionalmente e na busca por ações transnacionais como uma saída para se contrapor à precarização do emprego e às chantagens do capital internacional, de transferência de produção ou fechamento de fábricas.

\section{A crise e os reflexos para o sindicato}

O sindicato, para mim, (...) é uma empresa como uma outra qualquer, independente. O quê que ela faz? O sindicato presta serviço, para o trabalhador através da sua mensalidade (...). O que quê o sindicato tem que fazer? Tem que prestar um serviço de qualidade, né. O sindicato tenta, tenta prestar um serviço de qualidade e tal (sic) (Entrevista $n^{\circ} 5$ com dirigente sindical, ago. 2004). 
Essa idéia de que o sindicato é uma empresa prestadora de serviços e que deveria se conduzir como tal pode significar uma crise de identidade institucional, ainda que não visível e, à primeira vista, confirma teses de que o sindicato vive uma crise de identidade que poderá culminar na sua derrocada.

Esse fenômeno observado no sindicato local, no entanto, não pode ser generalizado para todo o sindicalismo. Convém lembrar que, a formação de identidades coletivas pode ser associada à "luta por direitos específicos. Direitos e identidades caminham juntos. Criar identidade significa criar um espaço de luta por direitos, a qual, por sua vez, cria identidades coletivas", como afirma Sorj (2001, p. 91). Identidades levam os sujeitos - trabalhadores e sindicato - a organizarem práticas que permitem a expressão de seus interesses, ainda que seja um processo permeado por contradições e conflitos.

Em épocas de crise ocorre a ampliação do papel dos indivíduos, como afirma Morin (s.d). Isso é visível nas instituições sindicais, nas quais os grupos que as dirigem definem a linha de atuação e adotam estratégias que se confundem com as do capital6. O SMC, por exemplo, se adaptou a uma linha de atuação pragmática, característica da central sindical a qual está filiado, mas substancialmente, traz a marca do corpo que o dirige. Este sindicato, em vez de derrocada, revitalizou-se em vista da ampliação da base metalúrgica com a vinda das montadoras, mas fundamentalmente devido a ação e pressão dos trabalhadores.

O desemprego industrial e o encolhimento de categorias profissionais, a partir dos anos 1970, levaram muitas instituições sindicais a adotarem a luta pelo emprego como bandeira principal e que, associadas ao avanço da ideologia neoliberal, contribuíram para o embaraçamento do papel histórico de um sindicato de trabalhadores. O sindicato foi concebido por alguns dirigentes como "um instrumento de luta para desenvolver o capitalismo brasileiro", como disse Magri (FSP, 29/08/1987 apud Núcleo de Piratininga de Comunicação. s.d.), o que demonstra a busca pela auto-preservação do sindicato no cenário de crise econômica.

Além do desemprego ser elemento desmobilizador da luta sindical; ele ainda é subrepticiamente utilizado pelo capital para conter as reivindicações. Os sindicatos são acusados de impedir a criação de empregos, sendo colocados numa situação crítica, na medida em que são forçados a aceitar a redução de direitos sob a chantagem da transferência da produção para outros países. A mobilidade do capital industrial e a volatilidade financeira parecem ser a

\footnotetext{
${ }^{6}$ Nesse cenário de transição, o estudo do microcosmo social readquire importância, porém de modo interrelacionado com os movimentos de nível macro-estruturais, transnacionais, mundiais, nacionais, regionais etc.
} 
novidade que desafia o sindicato a redefinir suas estratégias de ação. O desemprego ao reduzir as bases e filiados, motivou muitos sindicatos, entre as quais o local, a fundar parte significativa de suas ações para garantia de emprego. Nessa linha, o sindicato amplia seu raio de ação, na medida em que se atribui a ele o papel de

\begin{abstract}
cobrar das esferas [públicas], para que ajude também os pequenos e microempresários. Porque se nós não fizermos, nós não vamos garantir o emprego. O que vai adiantar a gente ficar batendo? Daqui a pouco as empresas não são competitivas, não têm emprego, não têm sindicato! Sindicato forte é quando tem bastante emprego, abundância. Quando não tem emprego ou dá desemprego (...) é obrigado a aceitar muitas coisas (Entrevista n. 5 com dirigente sindical, ago.2004, grifos nossos).
\end{abstract}

A falta de emprego, portanto, desemboca numa crise, na qual, o papel original do sindicato começa a se transformar para que o trabalhador empregado e o sindicato continuem a existir. Identifica-se um embate para que os empregos sejam mantidos a qualquer custo, mesmo trazendo perdas de conquistas históricas para os trabalhadores, como redução de salários, a introdução de remuneração, jornada e contratos flexíveis e outros. Isso confunde a ação do sindicato e soma-se à fragmentação da categoria como classe social histórica.

Além disso, outras tarefas recaem sobre o sindicato: "A aposentadoria caiu sobre o sindicato, saúde, educação, qualificação, assistência, lazer. (...) O sindicato ficou preso numa seguinte situação: suas bases objetivas retraem, o emprego formal, salário etc. E, ao mesmo tempo, as tarefas que competem a eles são maiores, então, hoje, essa que é a realidade desse sindicato" (Entrevista $\mathrm{n}^{\circ} 4$ com assessor sindical, jul. 2004). Com a fragilização do Estado Social nos países desenvolvidos e suas consequiências na configuração do Estado, nos países subdesenvolvidos, os sindicatos assumem responsabilidades da esfera pública, para as quais eles não se acostumaram ao longo de um século:

Sindicato não entende de desemprego, ele trabalha com o trabalhador! (...) O aprendizado pelo sindicato do desemprego é o aprendizado mais doloroso, que é como a perda de um filho. (...) O dirigente sindical pensar no desempregado é mesma coisa que um pai pensar num filho morto. (...) Ele tem que fazer um esforço para entender aquele fato, que aquele fato é a negação de algo que é a expressão dele (...), ele está pensando a extinção dele mesmo. Então imagina o dirigente pensar o desempregado. Para ele o desempregado é muito mais do que a negação dele, é a negação dele e do projeto dele, da projeção dele na vida (Entrevista $\mathrm{n}^{\circ} 4$, com assessor sindical, jul. 2004). 
Em termos gerais, a crise de identidade institucional decorre da "nova" configuração do mercado de trabalho e da classe trabalhadora, tornando ultrapassados os objetivos tradicionais dos sindicatos. Frente às mudanças estruturais no interior do trabalho é exigido o redimensionamento de práticas e ações. Isso se reflete na demanda por um novo perfil de dirigente sindical que, cada vez mais, precisa de qualificação para o enfrentamento das questões relativas ao trabalho.

Os sindicatos encontram-se em constante posição de descobrir quais são os seus interesses e como estes podem ser alcançados sem, contudo, revelarem-se contraditórios e autodestruidores de forma a ameaçar a sua existência. Segundo Offe e Weisenthal (1984), os sindicatos, estão sujeitos a percepções falsas das necessidades da categoria que representam. A probabilidade de distorção dos interesses da classe trabalhadora é maior do que a das classes capitalistas, especialmente nesses tempos de açodamento do neoliberalismo e do aparato midiático na direção da redução dos direitos. Dessa forma, um dos desafios centrais para os sindicatos hoje está em manter sua identidade historicamente constituída e organizar as necessidades de suas respectivas categorias, mas especialmente, buscar diminuir a fragmentação dos trabalhadores, distinta da tradicional fragmentação operária e que sinaliza uma crise, talvez a mais aguda no presente, que é a da utopia da igualdade.

A busca pela universalização dos direitos dos trabalhadores entrou em crise. As transformações que se processaram no mundo do trabalho e, particularmente, na organização e formatação da indústria automotiva, num cenário de flexibilização possibilitou aquilo que Ferraz (2005), identificou para o momento, como a perda do referencial universal dos direitos. Esse se processou pela redução da abrangência dos mesmos em que a diversidade de situações e de segurança no trabalho, dentro de uma mesma categoria, "sugere a implosão do quadro de referência que organiza a vida dos indivíduos. Essa diversidade tende a ser vivida como aleatoriedade e, na falta de um princípio de igualdade que organize e forneça sentido para a desigualdade, esta passa a ser vivenciada como simples diferença natural” (Idem, p. 14).

A dificuldade de universalização dos direitos dos trabalhadores é o grande desafio que se coloca para os sindicatos num mundo globalizado.

O SMC, por exemplo, não pretende eliminar o capitalismo, mas atua no campo do capital e joga com as mesmas peças. Sua ação tem tido um duplo caráter: garante ganhos salariais aos trabalhadores e também se garante enquanto instituição de representação dos mesmos. Não se diferencia daquele sindicalismo numa estrutura fordista, pois ele objetiva aprofundar e ampliar, por meio da mobilização, benefícios e aumentos salariais em troca do 


\section{DIVERS@!}

cumprimento de metas, diminuição do absenteísmo e outras metas da empresa. Isso pode ser verificado pela análise dos acordos, nos quais se atrela parte da remuneração ao desempenho individual ou coletivo.

Apesar dos sinais analisados de crise de identidade institucional do ponto de vista teórico, o novo desempenho que o SMC adotou, a partir dos anos 1990, revela mais continuidade histórica, pois não mudou radicalmente seu eixo político mantendo a mesma espinha dorsal dos anos anteriores a 1980. Conservou alguns dirigentes sindicais e introduziu outros oriundos das montadoras e de outras empresas, porém se modernizou e redimensionou suas ações para um novo patamar de mobilização. Além disso, abandonou um caráter meramente assistencialista no sentido tradicional adotando uma posição mobilizadora, embora dentro dos limites circunscritos pela Força Sindical. Essa mudança deu-se por questões internas desse sindicato, a exemplo, a oposição sofrida por trabalhadores contrários ao grupo que estava à frente da entidade e, fatores externos, como a crise econômica e as mutações no trabalho e políticas.

Para finalizar o presente estudo, afirma-se que questões aparentemente semelhantes ao serem redimensionadas na realidade empírica revelam significados diversos, ambivalências e complexidades que não nos autorizam a pensar em terminalidades, pois a ação e reação do sujeito enredado pela crise sinalizam mudanças, reorganizações e adaptações de modo permanente.

\section{Referências}

ARAÚJO, S. M. de. Novas institucionalidades e ação dos metalúrgicos na indústria automobilística no Paraná. In: Workshop Indústria Automobilística e Território. Curitiba: UFPR, GETS/LAGHUR, 2004. CD-ROM.

ARRIGHI, G. O longo século XX. Rio de Janeiro: Contraponto; São Paulo: Editora UNESP, 1996.

BOITO JR., A. Política neoliberal e sindicalismo no Brasil. São Paulo: Xamã, 1999. 


\section{DIVERS@!}

BRIDI, M. A. Sindicalismo e trabalho em transição e o redimensionamento da crise sindical. Dissertação de Mestrado, Curitiba: UFPR, 2005.

CARDOSO, A. M. Trabalhar, verbo intransitivo: destinos profissionais dos deserdados da industria automobilística. Rio de Janeiro: FGV, 2000.

CASTEL, R. As metamorfoses da questão social: uma crônica do salário. Petrópolis : Vozes, 1998.

CASTELLS, M. O poder da identidade. São Paulo: Paz e Terra, 1999.

CHESNAIS, F.; DUMÉNIL G.; LEVY, D; WALLERSTEIN I. Uma nova fase do capitalismo? São Paulo: Xamã, 2003.

FERRAZ, M. Igualdade e diferença: desafios para o sindicalismo paranaense frente à pulverização dos acordos trabalhistas. Belo Horizonte: XII Congresso Brasileiro de Sociologia, 2005.

HARVEY, D. A condição pós-moderna: uma pesquisa sobre as origens da mudança cultural. São Paulo: Loyola, 1993.

HEINZE, R; HINRICHS, K; OFFE, C.;OLK, T. Diferenciação de interesses e unidade sindical: a política sindical frente a rupturas na classe operária. In: OFFE, C. (Org). Trabalho e Sociedade, v.1. Rio de Janeiro: Tempo Brasileiro, 1989, p. 113-130.

JACQUES, M. da G. Identidade e trabalho. In: CATTANI A. D. (Org). Dicionário crítico sobre trabalho e tecnologia. Petrópolis: Vozes; Porto Alegre: Ed. Da UFRGS, 2002.

KREIN, J. D. O Aprofundamento da flexibilização das relações de trabalho no Brasil nos anos 90. Dissertação de mestrado. Campinas: UNICAMP, 2001. 


\section{DIVERS@!}

MANZANO, S. Diagnóstico das condições de trabalho nas montadoras de veículos do ABC e no Paraná: Um estudo sobre a modulação da jornada de trabalho e PLR. Dissertação de Mestrado: UNICAMP, 2004.

MARX, K. O capital. 3. ed. Rio de Janeiro: Civilização brasileira, 1975.

MARX, K. e ENGELS F. O manifesto Comunista. In: Obras escolhidas. São Paulo: Editora Alfa-Ômega, s.d.

MELLO e SILVA, L. Trabalho em grupo e sociabilidade privada. São Paulo: Editora 34, 2004.

MORIN, E. Sociologia. Apartado 8/ Portugal: Publicações Europa-América, s.d

OFFE, C. e WEISENTHAL, H. Duas lógicas da ação coletiva: notas teóricas sobre a classe social e a forma de organização. In: Problemas estruturais do Estado capitalista. Rio de Janeiro: Tempo Brasileiro, 1984, p. 56-117.

RODRIGUES, L. Destino do sindicalismo. São Paulo: Edusp, 1999.

SORJ, B. Sociologia e Trabalho: mutações, encontros e desencontros. Revista Brasileira de Ciências Sociais, v. 15, n. 43, p. 191-229, jun. 2000.

SORJ B. A nova sociedade brasileira. Rio de Janeiro: Zahar Editor. 2001.

WEBER, M. Economia e sociedade. Brasília: Editora UNB, 1991. 